\title{
Food as harm reduction during a drinking session: reducing the harm, or normalising harmful use of alcohol? A comparative analysis of alcohol industry and non-alcohol industry-funded advice
}

Anna Ramsbottom ( $\nabla$ a.c.ramsbottom@gmail.com )

London School of Hygiene \& Tropical Medicine https://orcid.org/0000-0001-8277-5624

Mark Petticrew

LSHTM: London School of Hygiene \& Tropical Medicine

May van Schalkwyk

LSHTM: London School of Hygiene \& Tropical Medicine

Lauren Carters-White

The University of Edinburgh

Yasmine Benylles

The University of Edinburgh

\section{Research}

Keywords: Alcohol, Alcohol industry, Discourse analysis, Public health, Commercial determinants of health

Posted Date: August 4th, 2021

DOI: https://doi.org/10.21203/rs.3.rs-764214/v1

License: (c) (i) This work is licensed under a Creative Commons Attribution 4.0 International License. Read Full License 


\section{Abstract}

Background: The aim of this study was to critically analyse information concerning the relationship between alcohol and food consumption provided via alcohol industry (Al) funded and non-Al-funded health-oriented websites, to determine the role it plays within the alcohol information space, and how this serves the interests of the disseminating organisations.

Methods: Information on food as a harm reduction measure while drinking alcohol was extracted from the websites of $15 \mathrm{Al}-$ funded corporate social responsibility (CSR) organisations. As a comparison group, non-Al-funded health websites were also searched ( $n=16$ websites with food and alcohol-related content). Information on both the webpages themselves, and downloadable information sheets was included. Critical discourse analysis (CDA) was used to allow the text analysed to be situated within the broader political and social context.

Analysis was carried out iteratively, involving continuous comparison within and between websites. Discursive themes were identified by three researchers. Identified discursive elements were discussed to reach a consensus, and a final coding framework was then developed. "Tone" analysis was used to assess whether the overall tone within individual websites were considered to be pro-alcohol consumption, neutral or discouraging of alcohol consumption.

Results: There were some commonalities across Al and non-Al-funded websites, whereby both appeared to normalise alcohol consumption and to encourage use of food as a measure to enable sustained drinking, to avoid drinking in a way that results in short-term harms, and to prevent or "cure" a hangover. The fact that both Al-funded and non-Al-funded organisations shared many of these narratives is particularly concerning. However, discourse of food and alcohol that served to promote "moderate" drinking as beneficial to health, was used exclusively by Al-funded organisations, focusing on special occasions and individual blaming.

Conclusions: Alcohol consumption, including heavy and harmful consumption, is frequently normalised within the online information space. Emphasising food consumption may have the effect of supporting consumers to drink for longer periods of time. Health professionals and independent health organisations should challenge why Al-funded organisations, with a major conflict of interest, and a history of health misinformation, are often given the responsibility for disseminating health information to the public.

\section{Background}

Globally, alcohol use is the seventh leading risk factor for both deaths and disability adjusted life years (DALYs) (1). Effective alcohol harm reduction at a policy level focusses on interventions targeting the marketing, availability and pricing of alcohol. Population level interventions mainly focus on the provision of information, though labelling, and through education campaigns. The effectiveness of these is often limited, not least because labelling in many countries is self-regulated to some extend by the alcohol industry (Al) itself. The provision of information on alcohol harms also involves Al bodies, as well as independent public health actors, such as government agencies and NGOs. In the case of public health actors, the aim is to mediate the quantity and patterns of consumption that affect health (2).

One harm reduction approach which is frequently recommended by both Al-funded and independent organisations is the consumption of food while drinking. Food consumption is explicitly mentioned in the low-risk alcohol consumption guidelines of several countries, with the aim of providing guidance on how to keep short-term risks low during single occasion drinking (3) (4). However, the inclusion of such guidance varies, and, for example, is absent from Australian or US guidelines (5)(6)(7)(8).

The Al also disseminates information on this topic through corporate social responsibility (CSR) organisations which it funds (e.g. Drinkwise (Australia), and Drinkaware (Ireland, UK)). This includes advice on eating in order to reduce harm during a drinking session. The accuracy of this information has not been assessed, though analysis of other health-related information funded by the Al has found that it misrepresents and omits evidence of harms in relation to cancers, cardiovascular disease (CVD), and the risk of harms in pregnancy (9)(10)(11)(12). There is also evidence that Al-funded organisations disseminate 
similar misinformation on alcohol harms and harm reduction to schoolchildren through its school-based programmes in the UK and other countries (13).

The aim of this study was to critically analyse the discourses articulating eating as a form of alcohol harm reduction, and to compare Al-funded and non-Al-funded materials. Our overall aims were to (i) systematically compare the available information on industry and non-industry funded information and to determine whether and how these discourses differ; and (ii) if they differ, to assess how these discourses may establish and maintain systems of meaning and framing which may be favourable to industry interests.

\section{Methods}

\section{Data sources}

Al-funded organisations predominantly disseminate information through their company websites, and the websites of CSR organisations which they fund (e.g. Drinkaware). We identified such organisations by searching the CSR sections in English language alcohol producers' websites and from previously published lists (14). After excluding inaccessible websites and those without food and alcohol-related content, the websites of 15 industry-funded organisations were available for analysis. As a comparison group, non-Al-funded health websites were also searched ( $n=16$ websites with food and alcohol-related content), and all information on food consumption as a harm reduction measure while drinking alcohol was extracted from both types of website. Information on both the webpages themselves, and downloadable information sheets was included.

For information on a webpage to be extracted for analysis, it had to mention the consumption of food in relation to modifying the effects of alcohol consumption. Information relevant to the wider discourse of the subject was also extracted, for example information on the context and nature of "binge drinking" in relation to food, and the health risks associated with such behaviour. All relevant text was extracted into tables by one researcher, with a second researcher independently checking the original data source for accuracy.

\section{Analysis methods}

Critical discourse analysis (CDA) was used to allow the text analysed to be situated within the broader political and social context (15). Discourse has contrasting definitions in the literature (16), and this study adopted Fairclough's definition as "particular ways of representing particular aspects of social life" (16). Discourses may be used as a mechanism by which ideologies are legitimised and so help maintain domination of a subject area (17). However, such dominance is open to critique and CDA provides a way of identifying such dominant assumptions in order to demonstrate the implications of those assumptions (17). In this way, CDA aims to capture the relationships between the micropolitics of the information being disseminated by both Al-funded and non-Al-funded organisations and the macropolitical landscape of power structures and ideology in which it sits (18).

In order to help uncover the dominant discourses, data were organised into themes. Dominant narratives were those deemed to carry influential messages due to the context within which they were disseminated, and the consistency with which they were mentioned. Analysis was carried out iteratively, involving continuous comparison within and between websites. This approach allowed for the discourses to be systematically identified.

Discursive themes (or "codes"; short summaries of topic areas) were identified by three researchers (AR, MP and MvS). The discursive elements which were identified were discussed to reach a consensus and a final coding framework was then developed.

An extraction table was developed based on the identified themes, allowing extraction of supporting quotes. The extraction table was piloted by three researchers (MvS, MP and AR) on content from four websites (two Al-funded and two non-Al-funded). One researcher (AR) then systematically analysed all information, identifying all relevant text and iteratively ascertaining any further discursive elements as generated through the analysis process. Any additional analytical elements identified through

Page $3 / 11$ 
this iterative process were discussed among the researchers to reach consensus on their inclusion. AR then re-read the entire dataset, coding the data with this more comprehensive coding framework, and organising themes into overarching discourses using an inductive process as the dataset was analysed. These were discussed amongst the researchers (AR, MP, MvS), with any disagreements resolved through discussion.

\section{"Tone" analysis}

Previous analyses looking to understand the influence of industry and other organisations on research and policy development have analysed the "tone" of articles, for example those reporting on tobacco industry funded not-for-profit organisations (19). We conducted a similar analysis, to assess whether the overall tone within individual websites were considered to be proalcohol consumption, neutral or discouraging of alcohol consumption. Two researchers (LCW and YB), who were not involved in the primary analysis, reviewed all text from the 31 websites. The text was anonymised in relation to the name and type of organisation. A random sample of five articles were selected and coded by an additional four coders, in order to assess interrater reliability.

\section{Results}

The text focusing on food consumption and alcohol consumption and health-related outcomes was analysed from $15 \mathrm{Al}-$ funded websites and 16 non-Al-funded websites. The discourses identified in the materials are described below with example illustrative quotes.

1. Food and "moderate drinking" as part of everyday life

Food and alcohol consumption were frequently discussed together in both Al-funded and non-Al-funded websites, presenting alcohol consumption with food consumption (an essential activity done daily) as a part of everyday life. For example, by associating alcohol with mealtimes, an alcoholic drink is sometimes portrayed (by both Al-funded and non-Al funded organisations) as a normal part of the everyday routine, particularly with meals:

"It is better to drink wine moderately and regularly with the meals than to drink the same amount on a single occasion, and without any food." (Wine in Moderation, Al-funded)

"On the other hand, many people enjoy the taste of alcoholic beverages. And when consumed by adults in small to moderate amounts, especially with meals, alcohol may be good for the heart."(WebMD, non-Al-funded)

It is not clear from the accompanying text why alcohol is associated with food within these websites, and there is no evidence drawn upon or cited within the discourses to substantiate statements claiming it may be healthy "especially with meals", as in the case of WebMD.

"Moderate" drinking, featured often in these materials. "Moderate drinking" like "responsible" drinking is a vague term that is exploited by the $\mathrm{Al}(20)$. The concept of moderate drinking is subjective, inevitably conceived differently by readers, with many interpreting "moderation" to be their own current level of consumption (21). In these documents, "moderate" alcohol consumption was often presented, almost exclusively by Al-funded organisations, as part of a healthy lifestyle along with a healthy diet and exercise. Regular and moderate alcohol consumption was sometimes discussed in relation to the Mediterranean diet, a dietary pattern which is well-established to have health benefits (22):

"When enjoyed in moderation, alcohol can be part of a healthy lifestyle that includes good diet and exercise." (Beam Suntory, Alfunded)

"The moderate and daily intake of wine, usually red, during meals is also integral to the Mediterranean diet. Previous research studies have found a positive association between sticking closely to this kind of eating regimen and increasing life expectancy, as well as lowering the risk of debilitating diseases such as cardiovascular disease, type 2 diabetes, Metabolic Syndrome and dementias such as and Alzheimer's disease" (Wine in Moderation, Al-funded)

Page $4 / 11$ 
The association of regular, moderate drinking with this diet may imply that people should consider it an integral part of a healthy diet. The health benefits are uncertain given methodological and other biases in the evidence, and the epidemiological evidence suggests that any benefits from alcohol consumption, if they exist, are likely to accrue at very low levels of consumption, and apply only to risk of CVD. They do not apply to the risk of cancer, which increases at any level of consumption.(5).

2. Eating to slow absorption, and to drink for longer

The concept of food playing a protective role in the consumption of alcohol, as a mechanism by which to manage alcohol consumption, was a strong discursive frame emerging from both Al and non-Al-funded websites. This frequently emphasised the need to slow down the absorption of alcohol and, in some cases, to extend the drinking "moment". This discursive frame was seen more commonly within the Al-funded websites:

"Serving both food and drinks also makes the occasion more fun. You drink more slowly when you eat as well!" (Bacardi "slow drinking" website, Al-funded)

"In addition to enjoying the tastes, eating helps to slow down the absorption of alcohol in the blood. It's perfect for making the moment last longer by delaying the effects of the alcohol!" (Bacardi "slow drinking" website, Al-funded)

"Eat up. Don't drink on an empty stomach. Eat something preferably carbohydrates- before you start drinking and snack between drinks. Eating slows alcohol absorption and gives you more energy to enjoy yourself." (Heineken website, Al-funded)

Promoting eating, as a mechanism to slow absorption of alcohol, was observed in the discourses adopted by both Al and nonAl-funded organisations. Many texts, from both types of organisation, recommended eating before consuming alcohol in order to avoid drinking on an empty stomach. Some organisations provided reasons for this, for example to delay alcohol entering the bloodstream, while others did not:

"if your child is going to drink, give them starchy food (like bread or pasta) so they won't be drinking on an empty stomach" (Northern Ireland Direct, non-Al-funded)

"eating before you start drinking will help you the most. That's because if you drink on an empty stomach, the alcohol will enter your bloodstream almost immediately." (DrinkiQ (Diageo), Al-funded)

"Eat a decent meal if you're going to be drinking alcohol-food slows down the rate that alcohol is absorbed into the bloodstream." (Drinkaware, Al-funded)

"Pace [:] Encourage them to take their time to taste and enjoy their drinks rather than rushing or downing them." (Drinkaware, Alfunded)

"Drinking over several hours as well as eating will have a lesser effect on your blood alcohol concentration." (Aware.org, Alfunded)

"Eat before and while you drink [:] Eat a good meal before you start drinking, or enjoy some snacks while you drink. This helps to slow down the effect of alcohol on your body." (Alcohol Focus [Scotland], non-Al-funded)

The need for such mechanisms to extend drinking and slow the absorption of alcohol appears to be based on the assumption that people wish to drink multiple alcoholic beverages and prolong the drinking "window". The provenance of this assertion is not discussed in the discourses, instead it is presented as a given, or an accepted norm. Slowing down the immediate effects of alcohol consumption and "making the moment last longer" may serve to increase consumption, if people are able to keep drinking steadily over longer periods of time.

3. Food to prevent and cure a hangover

Page 5/11 
Food intake when consuming alcohol was also framed as a way of preventing a hangover and various websites also described the role of food as being a "cure" or a "treatment" for hangover symptoms. The majority of websites that mentioned hangovers suggested mechanisms to prevent hangover and hangover cures:

"Avoid alcohol on an empty stomach as it increases the risk of experiencing hangover symptoms. Food helps slow down the rate your body absorbs alcohol." (Drinkaware, Al-funded)

"How can you cure a hangover?

As well as water, drink fresh juice to give yourself a vitamin boost. If you really need it, take a painkiller and an antacid to settle your stomach and alleviate hangover symptoms. Try a rehydration treatment sachet - they replace lost minerals and salt.

Eat something - bananas and kiwis are examples of food you can eat to help cure a hangover as they are a source of potassium (a mineral you lose when you drink because of the diuretic effect of alcohol)." (Drinkaware, Al-funded)

"Follow these tips to keep hangovers away.

Don't drink on an empty stomach. Before you go out, have a meal that includes carbohydrates (such as pasta or rice) or fats. The food will help slow down the body's absorption of alcohol." (NHS Direct Wales, non-Al-funded)

However, there was one non-Al-funded website that discussed hangover "cures" as myth:

“Can you 'cure' a hangover?

Hangover cures are generally a myth. There are no cures for a hangover. All you can do is ease the symptoms and wait until it goes away." (Health Direct [Australia], non-Al-funded)

This theme of hangover prevention was seen across both Al-funded and non-Al-funded websites and may unintentionally serve to normalise hangovers. This is despite the fact that to experience a hangover, people would likely need to be consuming alcohol well above guideline levels. While eating before or during alcohol consumption may slow the absorption of alcohol and may lower the blood alcohol concentration (BAC) at any one time (23), it will not affect the overall amount of alcohol entering the bloodstream (24). However it may speed up metabolization of alcohol and reduce the likelihood of a hangover, though there is surprisingly little research on this (25).

4. "Responsible" alcohol consumption

"Responsible" alcohol consumption was a dominant discursive frame emerging from the analysis. "Responsible" drinking is a term almost exclusively used by industry or industry-funded organisations that is purposefully ambiguous and stresses individual responsibility, a common theme within the texts (20). As the 'Australian Guidelines to Reduce Health Risks from Drinking Alcohol' discuss, the idea of "responsible" drinking differs within different societal groups and could be considered a moral or normative standard rather than based on scientific evidence (8).

The responsibility of the individual, in terms of their behaviour while drinking, was a common theme, found almost entirely in Al-funded organisations. This was often accompanied, particularly in Al-funded websites, with a narrative relating to "control" and to the use of food to allow the individual to maintain control. Short-term negative consequences of drinking were also often emphasised in Al-funded websites as being the fault of the individual, who lacked knowledge or judgement:

"Don't drink on an empty stomach. A healthy meal before you go out or start drinking, and snacks between drinks can help to slow down the absorption of alcohol, helping you stay in control." (Drinkaware, Al-funded)

"Alcohol is a depressant - it can affect your reason, judgement and coordination, and slows down your reaction time. This means that if you drink to excess, you're putting yourself at risk." (Asahi website, Al-funded) 
"Studies show that many people, especially young people and women, underestimate the amount they drink because they do not know what constitutes a standard drink." (Educ'alcool, Al-funded)

"Drinking alcohol is a matter of individual judgement and accountability." (Asahi website, Al-funded)

"Those choosing to drink have a responsibility to get the facts about how alcohol affects them, and make smart choices when they consume alcohol." (Beam Suntory, Al-funded)

Finally, the calorie content of alcohol is discussed on a few websites, both Al and non-Al funded; this is not discussed further as it is not discussed in the context of consuming food as a harm reduction measure.

\section{"Tone" analysis}

The rated tone of the materials presented on these websites were found to be similar for Al-funded websites and non-Al funded websites (83.3\% of Al-funded websites, and $81.3 \%$ of non-Al-funded websites, adopted a tone which was assessed as "proalcohol"). The inter-rater reliability for the random sample of five articles selected and coded by four coders was high (70\%).

\section{Discussion}

This analysis found that there are clear differences and also some, perhaps surprising, similarities between the information on alcohol and food disseminated by Al-funded and non Al-funded websites. Both types of organisation appear to encourage using food as a measure to enable sustained drinking, and to help avoid drinking in a way that causes specific short-term harms. Discussion of longer-term harms is limited to CVD, where some Al-funded websites claim that alcohol consumption with food reduces cardiovascular risk. This claim represents a considerable overstatement of the evidence, as the evidence on CVD and alcohol is, at best, uncertain, and there is no good evidence that eating at the same time as drinking is cardioprotective, nor that wine reduces the risk, despite the claim by the "Wine in Moderation" website(3)(26).

There were also examples of recommending food as a method of preventing or curing a hangover. Such discourses were found almost entirely on the websites of Al-funded organisations. There also appears to be an implicit assumption in the messages from both Al-funded and independent organisations that consumers were looking for, and would benefit from, ways to be able to drink for longer, without immediate, adverse impacts, and that consumers were likely to drink in a way that would precipitate a hangover. Al discourses also typically suggested that "moderate" drinking with food had health benefits; focused on special events such as holidays; and focused on individual responsibility. This articulation of alcohol consumption was exclusive to Al discourses.

Overall, our findings suggest that both Al and non-Al organisations frequently appear to present information in a way that normalises alcohol consumption, while framing eating as a mechanism for individuals to "manage" the effects of alcohol consumption. This normalisation manifested in different ways, including through alignment with food, mealtimes, and in some cases the active encouragement towards consuming alcohol as part of a balanced diet.

The emphasis on "slow" drinking is a particular focus of Al websites. In this, eating is framed as making the experience of drinking more enjoyable both through enhancing taste, but also by slowing down and making the "moment last longer". It is unclear why "slow" drinking would be a goal for consumers, however, the tension between the Al's need to maintain and increase sales on the one hand, and to maintain its reputation on the other, may be one reason why it is promoted within Alfunded websites. Alcohol industry sales are highly dependent on people consuming alcohol to excess (27), yet industry must not be seen to perpetuate such high levels of alcohol consumption. As such, by including such "responsible drinking" guidelines on their websites, the Al are exerting a form of agenda-setting power as part of their broader CSR initiatives. It additionally allows the Al to achieve a well-used CSR technique of "innocence by association", whereby corporations associate themselves with good causes/PR campaigns to improve their public image (28).

Promoting heavy and/or sustained drinking, while reducing visible, short-term, overt harms is therefore a desirable strategy for the industry, i.e. through encouraging consumption of the equivalent or greater amount of alcohol, but over longer "sessions" 
and/or more regularly, and with food. Previous studies have demonstrated how industry seek to enact this strategy, for example, by showing how the industry frames messages of responsibility around the individual drinker and often focusses on a minority of "harmful drinkers" rather than on the majority of "moderate" drinkers (29). Such organisations also present "responsible drinking" as a behavioural, rather than health issue - that is, the drinker simply needs to moderate their behaviour while drinking, rather than actually drink less (30). Such discourses appear to establish a simplistic dichotomy between "good drinkers" who abide by the rules, and "bad drinkers", the minority who will not or cannot heed the advice prescribing how to "drink responsibly".

However, these narratives, while more prevalent and explicit in the websites of Al-funded organisations, were not limited to these organisations. Concerningly, there was also frequent messaging within non-Al-funded organisations that may normalise alcohol consumption, as discussed above, for example through aligning it with food and discussing "moderation" in vague terms. Both types of website also discussed the role of food in preventing or curing a hangover. This narrative may reflect an assumption that people are likely to drink in a way that will lead to a hangover, which may again contribute to normalising heavy drinking.

It is also notable that the narratives around hangovers, binge drinking and encouragement of "moderate" and "slow" drinking in Al-funded materials focused to a large extent on young people and drinking. By focussing on young people, this could, again, be seen as an attempt by the industry to avoid public displays of being drunk, consistent with previous findings (31).

Strategies that focus on navigating the use of a product, rather than trying to tackle the underlying causes, have been seen across other industries. One example is in the tobacco industry, where the use of personal responsibility frames deflect attention from corporate responsibility (32), thus protecting the industry against litigation, regulation and tobacco control measures (33)(34)(35). A similar approach is seen in the context of car-based transport systems and pedestrian safety. In the US, for example, in response to escalating harms to pedestrians, the focus has been on blaming the behaviours of pedestrians and, to a lesser extent drivers, who need to use ever more technological advances to improve and "manage" their individual behaviour when using the transport system, while the alternative, have far fewer cars on the road and slow those that remain down significantly, remains largely excluded from the discourse of feasible solutions (36)(37).

Among the strengths of this study are the use of discourse analysis, which offers a more critical perspective, allowing findings to be interpreted within their wider political and social context. This allows greater understanding of how specific discourse may work to promote certain ideas, ideologies and conceptualisations. The main weakness is that only website material was included - both public health bodies and Al-funded organisations have other means of communication that would also benefit from analysis (such as social media).

\section{Conclusions}

Our findings add to the evidence that alcohol consumption, and heavy and harmful consumption, is normalised within the online information space. Discussing harmful alcohol consumption in the context of food may contribute to this normalisation. It is essential that all online sources of information on these topics consider whether they are promoting pro-alcohol, proconsumption narratives, inadvertently or not. The fact that both Al-funded and non-Al-funded organisations shared many of these narratives requires further analysis. More immediately, independent health professionals and independent health organisations should continually challenge why alcohol-industry funded organisations with a major conflict of interest, and a history of health misinformation, have a role in disseminating health information to the public in the first place.

\section{Declarations}

\section{Ethics approval and consent to participate:}

$\mathrm{n} / \mathrm{a}$

\section{Consent for publication:}




\section{Availability of data and materials:}

$\mathrm{n} / \mathrm{a}$

\section{Competing interests:}

None

\section{Acknowledgements:}

No additional

\section{Funding:}

This research did not receive any specific grant from funding agencies in the public, commercial, or not-for-profit sectors. MP is a co-investigator in the SPECTRUM consortium which is funded by the UK Prevention Research Partnership (UKPRP), a consortium of UK funders [UKRI Research Councils: Medical Research Council (MRC), Engineering and Physical Sciences Research Council (EPSRC), Economic and Social Research Council (ESRC) and Natural Environment Research Council (NERC); Charities: British Heart Foundation, Cancer Research UK, Wellcome and The Health Foundation; Government: Scottish Government Chief Scientist Office, Health and Care Research Wales, National Institute of Health Research (NIHR) and Public Health Agency (NI)]. MvS is funded by the National Institute for Health Research (NIHR) Doctoral Fellowship (NIHR3000156) and her research is also partially supported by the NIHR Applied Research Collaboration North Thames. The views presented here are those of the authors and should not be attributed to the above funding organisations, their directors, officers, or staff.

\section{Authors' contributions:}

AR lead on the writing of the paper, and the analysis of the data; MvS, LCW and YB and MP contributed to the analysis and to the writing, to the data analysis and checking, and to the interpretation of the findings.

\section{References}

1. Griswold MG, Fullman N, Hawley C, Arian N, Zimsen SR, Tymeson HD, Venkateswaran V, Tapp AD, Forouzanfar MH, Salama JS, Abate KH. Alcohol use and burden for 195 countries and territories, 1990-2016: a systematic analysis for the Global Burden of Disease Study 2016. Lancet. 2018;392(10152):1015-35.

2. World Health Organization. Fact sheets: Alcohol [Internet]. World Health Organization. 2018 [cited 2020 Sep 22]. Available from: https://www.who.int/news-room/fact-sheets/detail/alcohol.

3. Department of Health. Alcohol Guidelines Review - Report from the Guidelines development group to the UK Chief Medical Officers [Internet]. London; 2016. Available from:

https://assets.publishing.service.gov.uk/government/uploads/system/uploads/attachment_data/file/545739/GDG_reportJan2016.pdf.

4. Butt P, Beirness D, Gliksman L, Paradis C, Stockwell T Alcohol and health in Canada: a summary of evidence and guidelines for low-risk drinking. Ottawa, ON; 2011.

5. Department of Health. UK Chief Medical Officers' Low Risk Drinking Guidelines. 2016.

6. Stockwell T, Zhao J, Thomas G. Should alcohol policies aim to reduce total alcohol consumption? New analyses of Canadian drinking patterns. Addict Res Theory. 2009;17(2):135-51.

7. Health.gov. 2015-2020 Dietary Guidelines: Appendix 9. Alcohol [Internet]. 2015 [cited 2020 Sep 22]. Available from: https://health.gov/sites/default/files/2019-09/2015-2020_Dietary_Guidelines.pdf. 
8. Australian Government National Health and Medical Research Council. Australian guidelines to reduce health risks from drinking alcohol. 2009.

9. Petticrew M, Maani Hessari N, Knai C, Weiderpass E. How alcohol industry organisations mislead the public about alcohol and cancer. Drug Alcohol Rev. 2018;37(3):293-303.

10. Lim AW, Van Schalkwyk MC, Hessari M, N., \& Petticrew MP. Pregnancy, fertility, breastfeeding, and alcohol consumption: An analysis of framing and completeness of information disseminated by alcohol industry-funded organizations. J Stud Alcohol Drugs. 2019;80(5):524-33.

11. Petticrew M, Maani N, Pettigrew L, Rutter H, Van Schalkwyk MC. Dark nudges and sludge in big alcohol: behavioral economics, cognitive biases, and alcohol industry corporate social responsibility. Milbank Q. 2020.

12. Peake L, van Schalkwyk MCl, Maani N, Petticrew M. (in press). Heart disease and alcohol: analysis of the accuracy and completeness of health information on alcohol industry funded websites. Eur J Public Health.

13. Jackson N, Dixon R. The practice of the alcohol industry as health educator: a critique. NZ Med J. 2020;133(1515):89-96.

14. Lim AW, Van Schalkwyk MC, Maani Hessari N, Petticrew MP. Pregnancy, fertility, breastfeeding, and alcohol consumption: An analysis of framing and completeness of information disseminated by alcohol industry-funded organizations. J Stud Alcohol Drugs. 2019;80(5):524-33.

15. Fairclough N. Discourse and social change. Vol. 10. Cambridge: Polity press; 1992.

16. Garoon JP, Duggan PS. Discourses of disease, discourses of disadvantage: a critical analysis of National Pandemic Influenza Preparedness Plans. Soc Sci Med. 2008;67(7):1133-42.

17. Fairclough N. Critical discourse analysis: The critical study of language. Routledge; 2013.

18. Luke A. 5. Beyond science and ideology critique: Developments in critical discourse analysis. Annu Rev Appl Linguist. 2002;22:96.

19. Watts C, Freeman B. "Where There's Smoke, There's Fire": A Content Analysis of Print and Web-Based News Media Reporting of the Philip Morris-Funded Foundation for a Smoke-Free World. JMIR Public Heal Surveill. 2019;5(2):e14067.

20. Maani Hessari N, Petticrew M. What does the alcohol industry mean by 'Responsible drinking'? A comparative analysis. J Public Health (Bangkok). 2018;40(1):90-7.

21. Pearson $\mathrm{H}$. The demon drink. Nature Publishing Group; 2004.

22. Sofi F, Abbate R, Gensini GF, Casini A. Accruing evidence on benefits of adherence to the Mediterranean diet on health: an updated systematic review and meta-analysis. Am J Clin Nutr. 2010;92(5):1189-96.

23. Jones AW, Jönsson K. Food-induced lowering of blood-ethanol profiles and increased rate of elimination immediately after a meal. J Forensic Sci. 1994;39(4):1084-93.

24. Watkins RL, Adler EV. The effect of food on alcohol absorption and elimination patterns. J Forensic Sci. 1993;38(2):28591.

25. Cederbaum Al. Alcohol metabolism. Clin Liver Dis. 2012;16(4):667-85.

26. Rehm J, Hasan OSM. Is burden of disease differentially linked to spirits? A systematic scoping review and implications for alcohol policy. Alcohol. 2020;82:1-10.

27. Bhattacharya A, Angus C, Pryce R, Holmes J, Brennan A, Meier PS, et al. How dependent is the alcohol industry on heavy drinking in england? Addiction. 2018;113(12):2225-32.

28. Dorfman L, Cheyne A, Friedman LC, Wadud A, Gottlieb M. Soda and tobacco industry corporate social responsibility campaigns: how do they compare? PLoS Med. 2012;9(6):e1001241.

29. Casswell S. Vested interests in addiction research and policy. Why do we not see the corporate interests of the alcohol industry as clearly as we see those of the tobacco industry? Addiction. 2013;108(4):680-5.

30. Petticrew M, Fitzgerald N, Durand MA, Knai C, Davoren M, Perry I. Diageo's' Stop Out of Control Drinking'campaign in Ireland: an analysis. PLoS One. 2016;11(9):e0160379. 
31. Petticrew M, Douglas N, D'Souza P, Shi YM, Durand MA, Knai C, et al. Community Alcohol Partnerships with the alcohol industry: what is their purpose and are they effective in reducing alcohol harms? J Public Health (Bangkok).

2018;40(1):16-31.

32. Friedman LC, Cheyne A, Givelber D, Gottlieb MA, Daynard RA. Tobacco industry use of personal responsibility rhetoric in public relations and litigation: disguising freedom to blame as freedom of choice. Am J Public Health. 2015;105(2):25060.

33. Kyriakoudes LM. Historians' testimony on "common knowledge" of the risks of tobacco use: a review and analysis of experts testifying on behalf of cigarette manufacturers in civil litigation. Tob Control. 2006;15(suppl 4):iv107-16.

34. McDaniel PA, Malone RE. Understanding Philip Morris's pursuit of US government regulation of tobacco. Tob Control. 2005;14(3):193-200.

35. Nathanson CA. Collective actors and corporate targets in tobacco control: A cross-national comparison. Heal Educ Behav. 2005;32(3):337-54.

36. Insurance Institute for Highway Safety Highway Loss Data Institute. Fatality Facts 2018 Pedestrians. 2018.

37. Insurance Institute for Highway Safety Highway Loss Data Institute. New studies highlight driver confusion about automated systems. 2019.

\section{Tables}

Table 1

Al-funded and non-Al-funded websites containing information on alcohol and food included in analysis

\begin{tabular}{|c|c|}
\hline Al-funded $(\mathrm{N}=15)$ & Non-Al-funded $(\mathrm{N}=16)$ \\
\hline - Aware.org & - Health.gov \\
\hline - Educ'alcool & - MedlinePlus (U.S. National Library of Medicine) \\
\hline - Heineken: Tips for Drinking Responsibly & - WebMD (USA) \\
\hline $\begin{array}{l}\text { - Foundation for Advancing Alcohol } \\
\text { Responsibility }\end{array}$ & - NHS (NHS Choices and www.nhs.uk) \\
\hline - DrinkWise (Australia) & - CMO Guidelines \\
\hline - Drinkaware (United Kingdom) & - Alcohol Focus (Scotland) \\
\hline $\begin{array}{l}\text { - International Alliance for Responsible } \\
\text { Drinking }\end{array}$ & - NHS Inform Scotland \\
\hline - IARD education site, Guidelines table & - NHS Direct Wales \\
\hline • DrinkiQ (Diageo) & - Northern Ireland Direct \\
\hline • Bacardi website, "slow drinking" & - Health Service Executive Ireland \\
\hline - Asahi website & - Department of Health, Australia \\
\hline $\begin{array}{l}\text { - Brown-Forman: Our Thinking About } \\
\text { Drinking }\end{array}$ & - Queensland Government \\
\hline - Beam Suntory & - Health Direct Australia \\
\hline - Wine in Moderation & - Government of Canada Health \\
\hline - $A B \ln B e v$ & $\begin{array}{l}\text { - Canadian Centre of Substance Abuse and Addiction: Low risk drinking } \\
\text { guidelines }\end{array}$ \\
\hline & - Ministry of Health (NZ) \\
\hline
\end{tabular}

